\title{
SINCE WE LAST SPOKE
}

by

Sophie Sabet

BAH in Art History, Queen's University, 2014

\author{
A Major Research Paper \\ presented to Ryerson University
}

in partial fulfillment

of the requirements of the degree of

Master of Fine Arts

in the Program of

Documentary Media

Toronto, Ontario, Canada, 2016

(C) Sophie Sabet 2016 


\section{AUTHOR'S DECLARATION FOR ELECTRONIC SUBMISSION OF A MRP}

I hereby declare that I am the sole author of this MRP. This is a true copy of the MRP, including any required final revisions. I authorize Ryerson University to lend this MRP to other institutions or individuals for the purpose of scholarly research I further authorize Ryerson University to reproduce this MRP by photocopying or by other means, in total or in part, at the request of other institutions or individuals for the purpose of scholarly research. I understand that my MRP may be made electronically available to the public. 


\section{Acknowledgements:}

Firstly, I would like to express my sincere gratitude to my advisors Edward Slopek and Sara Angelucci. Ed, thank you for the insightful discussions and encouraging my ideas from the beginning. Sara, thank you for guiding me throughout this whole process, your thoughtful feedback and support has been invaluable to me. I am grateful to you both.

To my mother, Asoudeh Novin and my father Abbas Sabet, I could not thank you enough for your unconditional trust, love and support. You are both such brave and strong individuals. I am eternally grateful to be called your daughter. Thank you both for everything you have given me. 


\section{CONTENTS}

PROLOGUE

CHAPTER 1: FAMILY HISTORY 2

The Family in Iranian Culture and My Family 2

After The Move: The Impact of Migration on Our Family 5

$\begin{array}{ll}\text { Project Description } & 9\end{array}$

CHAPTER 2: KEY CONCEPTS 11

Silence and Communication 11

$\begin{array}{ll}\text { Identification and Empathy } & 13\end{array}$

$\begin{array}{ll}\text { Private and Public Space } & 16\end{array}$

CHAPTER 3: METHODOLOGY 19

Before the Letters $\quad 19$

$\begin{array}{ll}\text { After the Letters } & 26\end{array}$

CHAPTER 4: RELEVANCE 33

CONCLUSION 36

$\begin{array}{ll}\text { IMAGE LIST } & 38\end{array}$

$\begin{array}{ll}\text { BIBLIOGRAPHY } & 43\end{array}$ 


\section{Prologue}

It was not until recent years that I noticed something curious about my family. That maybe the years of on going feuding and disappointment were not solely due to our conflicting personalities, and that there were other external, cultural and societal forces at play. When I began my MFA, I had no idea I was going to create a project about my own family - that I would be projecting giant portraits of my mother and father's face on gallery walls. But, over the last two years, the deep-seeded troubles my family ignored for as long as I can remember bubbled to the surface. Just as the chaos began to unfold, I started my MFA, trying to figure out what story I wanted to share with the world. It turned out that our story would be the one to tell. If there is one thing I am sure of, this story would not have been discussed and shared with the public, if it wasn't for the deep and unconditional love and trust we possess for one another. 


\section{Chapter 1: Family History}

\section{The Family in Iranian Culture and My Family}

To begin, I would like to discuss how the traditional Iranian family relates to my own family, a modern Iranian-Canadian household. Although my family does not fully reflect the Iranian family ideal, I believe it is worth exploring the similarities and differences that exist between the two. In Gender Differences in Traditional Attitudes Toward Marriage and the Family, Hojat states "The family network in Iranian traditional culture is considered as the most important factor bonding people together." ${ }^{\prime 1}$ This statement holds true to my family's way of being. Throughout my whole childhood, my parents were never keen on creating bonds with individuals outside our immediate family. We only depended on each other. This bond had its benefits, however as our expectations and aspirations diverged, we were sealed in a destructive and insular space. The traditional Iranian family is patriarchal. The father is the head of the household and it's economic provider, while the role of the woman is wife and caregiver. The woman's independent objectives are non-existent. ${ }^{2}$ In his chapter Management of the household the $13^{\text {th }}$ century writer Nasīr al-Dīn Tūsī states “the right wife is the man’s partner in material well-being and his replacement in managing the household in his absence, and the best of all wives in one endowed with patience, faith, chastity, compassion, modesty, and obedience.”3

\footnotetext{
${ }^{1}$ Hojat, Mohammadreza. "Gender Differences in Traditional Attitudes Toward Marriage and the Family : An Empirical Study of Iranian Immigrants in the United States." In Journal of Family Issues, 21(4), 2000, 420.

${ }^{2}$ Nassehi-Behnam, Vida. "Change in the Iranian Family." In Current Anthropology, 26(5), The University of Chicago Press, 1985, 557.

${ }^{3}$ Janan, Tina. "The Difficulties of Traditional Iranian Parents Have Raising Their First Generation Daughter in the United States." The Chicago School of Professional Psychology, 2013, 11 .
} 
However, since the $20^{\text {th }}$ century these roles have evolved and transformed within Iranian society. In Change and the Iranian Family, Nassehi-Behnam states "After 1925, a number of related socioeconomic phenomena began to emerge in Iran, industrialization, juridical and administrative reform, urbanization, democratization and secularization of education, and introduction of mass media of communication are only the highlights of a profound transformation of the mental and sociocultural structure of the society of the time." ${ }^{4}$ The impact of modernization punctured the traditional Iranian familial structure. For instance, the wife now possessed the right to acquire an education and to work without her husband's consent. Further, the wife was now granted the right to divorce, although this law still has its limitations. Despite, these sweeping transformations within the family construct, traces of dated ideologies still linger within the modern Iranian home. My father is the main economic provider of our family. This position as breadwinner endows him with great joy, pride and power. Having his own company in Iran built from the ground up - added to his sense of pride, manhood and social status. With that said, my mother also works. She grew up in an upper middle class household, was well educated and was surrounded by art and culture throughout her whole upbringing. My mother broke through numerous cultural and societal barriers. She studied in France and acquired a degree in Mechanical Engineering and she is a visual artist who has had numerous exhibitions in Iran. The traditional Iranian female ideal did not align with the objectives she had set for herself. Thus, from the beginning of their relationship, my father's role as ultimate provider and head of the family was challenged.

\footnotetext{
4 Nassehi-Behnam, Vida. "Change in the Iranian Family." 558
} 
Perhaps my mother's ambition to live a fully independent life provoked her decision to immigrate to Canada. Maybe it was the fact that she had two daughters and didn't want them to face the same unjust challenges she confronted as a woman in Iran. Or perhaps it was the combination of the two. Either way, my mother and father made the choice to immigrate to Canada. I believe it is important to note that it was a choice to move rather than an involuntary circumstance. I do not want to deny or ignore our privileged position. With that said, our socioeconomic status could not fully protect us from the challenges ahead. 


\section{After The Move: The Impact of Migration on Our Family}

Each member in my family has been confronted with challenges exclusive to them due to our immigration to Canada. Personally, immigrating to Canada from Iran at the age of two meant that I was raised in a household that held different values from that of the codes of behavior prevailing in Canadian society. Thus, the manner in which I performed within the home often conflicted with the way I performed outside the home.

Nonetheless, I was confronted with the responsibility of creating a space that supported and nurtured my altering selves, whether that was the space within the domestic sphere or the space that landed outside those borders. Prior to moving to Canada my parents were well-established adults in Iran. They were each raised in a home that enforced a culture and value system parallel to the society it belonged to. Their relocation from East to West fractured the harmony between home and society. Our family home fostered a culture that was consistently being challenged by Canadian values. The confusion caused by displacement has particularly affected my father. Unlike my mother, sister and myself, my father has not fully relocated his life from Iran to Canada, physically and mentally. To this day he is a business and homeowner in Iran. His commitments in Iran have obliged him to consistently and periodically make lengthy business trips to Iran since our arrival to Canada. He has established a dual life, never fully committing himself to either world. For my father, owning a home in a western country benefitted his status as a successful businessman in Iran. His stay in Canada would be temporary. Why should he sacrifice his position as a dominant male figure by leaving a country that benefits him? Jalili states "Iranians identify with their occupations and take great pride in their careers. 
Therefore, they will not perform a job that they consider beneath them." ${ }^{, 5}$ If my father were to fully relocate to Canada and give up his position as a head of a company, he would be forced to start from scratch. His role as a provider would be jeopardized and his pride punctured. Further, Iranians are known to possess great national pride. "Iranians in general and those in the United States in particular prefer to identify themselves more by their national pride as the inheritors of the great Persian civilization and an ancient Persian culture..."6 A large part of my father's identity is linked to his nationality. By giving up his place in Iran, he is at risk of loosing part of who he is. In Mourning and Melancholia, Freud discusses how we not only mourn the departure of loved ones but also the loss of ideas, "Mourning is regularly the reaction to the loss of a loved person, or to the loss of some abstraction which has taken the place of one, such as one's country, liberty, an ideal, and so on." ${ }^{, 7} \mathrm{He}$ continues to state that for some, these conditions produce melancholia instead of mourning, which is said to be a pathological condition. I believe that everyone in my family has been subjected to a form of loss, whether it is a loss of an ideal or a loss of home, our inability to effectively mourn our losses has coated our home with a layer of melancholy. My father's disinterest to fully commit to a life in Canada has positioned both him and our family in a desultory state. According to Ghaffarian "acculturation is the process through which an individual adapts to a different

\footnotetext{
5 Jalali, Behnaz. “Iranian Families.” In M. McGolderick, J. K. Pearce, \& J. Giordano (Eds.), Ethnicity and family therapy, New York: The Guildford Press, 453.

${ }^{6}$ Hojat, Mohammadreza. "Gender Differences in Traditional Attitudes Toward Marriage and the Family : An Empirical Study of Iranian Immigrants in the United States.” 420.

${ }^{7}$ Freud, Sigmund. "Mourning and Melancholia." In The Standard Edition of the Complete Psycho-Analytic Movement, Papers on Metapsychology and Other Works, 243
} 
culture different from the one in which he or she was born and raised." ${ }^{\prime 8}$ Since my father perceives his relocation to Canada as a temporary endeavour, he has implicitly resisted adapting to the host-country, causing intra- and interpersonal conflict.

My mother's approach to the move differed from that of my father's. For my mother, the Canadian political landscape aligned with her political and social beliefs. My mother chose to immigrate to Canada with the intention of fully adopting this new environment. Since her arrival to Canada in 1995, she has not returned to her homeland. According to Sherif, "changing one's attitude to become consistent with the social norms of the host culture in one approach to reducing dissonance." ${ }^{, 9}$ Since my mother values Canada's social and political system, she has had less difficulty adapting. The friction between Canadian culture and Iranian culture is not the ultimate cause of her apprehension. Rather my mother's strain is the result of diverging expectations between her and my father and the inability to see eye-to-eye when it comes to what constitutes home. In Acculturation Style and Psychological Functioning in children of Immigrant, Pawliuk reports that family conflict can arise when some family members represent more of the host cultural values and others represent more their original cultural norms. ${ }^{10}$ It is evident that not every member of my family shares similar attitudes towards our move to Canada. This gap in expectations has become wider and more evident throughout the years and has now reached a breaking point.

\footnotetext{
${ }^{8}$ Ghaffarian, Shirin. "The acculturation of Iranian immigrants in the United States and the implications for mental health.” In The Journal of Social Psychology, 138(5), 650.

${ }^{9}$ Sherif, Carolyn W; Sherif, Muzafer; Nebergall, Roger E. Attitude and attitude change: The social judgement-involvement approach. Greenwood Press, 1965.

${ }^{10}$ Pawliuk, Nicole, et al. "Acculturation style and psychological functioning in children of immigrants." In American Journal of Orthopsychiatry, 66(1), 1996, 112.
} 
Displacement is the fundamental condition distressing our family; it has generated a fragmented family. Over time our individual struggles spawned from displacement has alienated us from one another. This project has created a platform where we can locate, communicate and try to understand our contrasting positions. 


\section{Project Description}

My approach in interpreting our story is an integral part of my project. Since We Last Spoke is an experiment I've conducted with my mother and father. The focus of the piece is my parents' relationship. Through a contemplation of their marriage, I was able to initiate a conversation regarding our family's silent past, our present struggles, and our future aspirations. I have utilized objects, spaces and a single instruction to guide and illustrate the piece. Since We Last Spoke does not intend to inform the viewer or our story, rather the work aims to immerse the viewer into our experience.

The three-channel installation is comprised of two components: The Letter Reading and The Bedroom Scene.

\section{The Letter Reading}

For this component of the installation, I asked my parents to choose and read an old letter they had written to one another early in their relationship. The period in which the letters were written coincide with the period in which we relocated from Iran to Canada. I proceeded to film a close up shot of each of their faces as they listened and reacted to the other person reading the chosen letter. The sound of each reader is intentionally removed so that all that is displayed in the final piece is the silent and emotional facial responses to the letters. 


\section{The Bedroom Scene}

This scene is set in my parent's bedroom and is layered with audio of a fragmented conversation between my parents. Although it is my parents, the recorded audio is also emblematic of an intimate argument between a married couple. As such, I have edited out specifics of their relationship but left in general frustrations regarding their current situation.

The content and form work in conjunction to reveal essential concepts present in the video. In the next chapter I would like to discuss the key concepts that have emerged as a result of the interplay between form and content. 


\section{Chapter 2: Key Concepts \\ Silence and Communication}

Both The Letter Reading and The Bedroom Scene explore different modes of communication. In The Letter Reading the letters are documents that represent past dialogues between my parents. Although writing allowed them to communicate while being physically apart, they also chose to write to one another while they were physically together. Through writing they were able to communicate their thoughts without risking emotional irruptions caused by person-to-person confrontation. Revisiting these letters thirty years later awakened memories of their former lives and resumed forgotten conversations. The letters are mementos of distant exchanges that reveal past uncertainties and aspirations for the future. The Letter Reading also explores the absence of communication. By excluding the audio in this piece I have emphasized the presence of silence. The silence not only asks the audience to read the piece differently but it also symbolizes the silence associated with shame and guilt. bell hook's discusses the importance of the confessional mode in her book Outlaw Culture: Resisting Representation, “ ...truth is also liberatory. The very thing one lies about is usually something one is ashamed about. And this shame basically enslaves people to the status quo." ${ }^{\prime 11}$ Failure to actualize the life they hoped to achieve in Canada has spurred feelings of contempt and prevented constructive conversations from taking place.

The Bedroom Scene explores communication through a different method. In this instance

\footnotetext{
${ }^{11}$ hooks, bell. Outlaw Culture: Resisting Representation, Routledge Press, 1994, 224.
} 
they are isolated from the outside world and are forced to address each other directly. Although the bedroom suggests physicality, I have excluded the portrayal of my parents' bodies in this scene. Rather there presence is realized by their voices. The bedroom becomes the embodiment of a dialogue. This formal decision is an attempt to emphasize the urgency in their tone and the meaning in their words. In both these pieces I aim to identify and expose through form, the different ways my parents communicate and understand one another. 


\section{Identification and Empathy}

I'm interested in discussing the spectator's relationship with the installation and how empathy is elicited in the piece. The term identification is used extensively to describe the experiences of viewers looking at film. According to French theorist Christian Metz identification takes place when the viewer suspends disbelief in the fictional world of the film and identifies not only with specific characters but also with the film's overall ideology. ${ }^{12}$ When looking at the portraits of my parents, it is certainly possible that the spectator's sense of self can be lost in the other as they identify with either my mother or father. However, I believe a more accurate term that describes the spectator's relationship with my parents would be what Carl Platinga calls "character engagement." Plantinga states, "Engagement allows for empathy and antipathy, sympathy and indifference, and certainly implies no melding of minds or identities." ${ }^{\prime 13}$ The audience has been invited to experience a fraction of my family's life. In the letter reading, the viewer is confronted with projected portraits experiencing an intense emotional state, there is no audio to provide guidance. I have stripped these two people of most identifiable characteristics. I hint at the fact that they may be a couple, since they occupy the same space and are framed by a bed. My father's skin complexion suggests his foreign identity. The piece offers limited information; nothing is definitive and everything is suggested. A relatable space is opened where viewers can insert their own individual narratives. My mother and father's interior emotional experience is the locus of attention. Film theorist Bela Belaz

\footnotetext{
12 Sturken, Marita; Cartwright, Lisa. Practices of Looking: An Introduction to Visual Culture, Oxford University Press, 2001, 73.

${ }^{13}$ Plantinga, Carl; Smith, Greg M. Passionate Views: Film Cognition, and Emotion. The Johns Hopkins University Press, 1999, 244.
} 
claims that "the expressive movement, the gesture, that is the aboriginal mother-tongue of the human race." ${ }^{\prime 14}$ My mother and father's facial gestures and expressions communicate information about their emotional state to the spectator. Vocal language is not required. The viewer may not recognize every emotional state my parent's are experiencing. Psychologist Paul Ekman claims that facial expressions are universal for central emotions such as fear and sadness, "there seems little basis for disputing the evidence that for at least five emotion categories there are facial behaviors specific to each emotion and that these relationship are invariant across cultures. ${ }^{" 15}$ Thus a silent dialogue is initiated between the viewer and my parents. Besides communicating their emotions, their facial expressions have the capacity to elicit affective response, such as an empathetic response. Plantinga states this is possible through the process of affective mimicry, facial feedback and emotional contagion. ${ }^{16}$ According to Platinga, emotional contagion is when learn to feel each other's emotions. It is possible to understand and feel another's emotion by viewing their facial gestures. Affective mimicry takes place when we mimic the facial expressions of those with whom we interact. Finally, facial feedback is when we catch the emotion we are mimicking. By simply being exposed to my parent's facial expressions the viewer is susceptible to their own emotional states. The degree to which they are susceptible can depend on the viewer's emotional state prior to entering the gallery. Formal elements strengthen the possibility of empathetic response. Scenes of empathy incorporate closer head shots as they focus the viewer's attention to the characters interior state. The duration of the shot is also an integral element. The more time the viewer spends with the shot the more likely they are to respond. In the letter

\footnotetext{
14 Ibid, 239

15 Ibid, 242

16 Ibid, 242
} 
reading, I have taken into account both these formal requirements. The portraits consist of clear, large head shots of my parents' faces. There is barely anything else in the scene to draw attention away from their facial expressions. Further, both scenes play for approximately five minutes, giving the audience plenty of time to engage and respond. Empathy is the capacity to recognize, feel and respond to what another is feeling. We undertake a mental simulation by which we imagine and dwell on the other's condition. We don't necessarily imagine being the character as we would in the process of identification but we imagine what they are thinking and feeling. I believe that the portraits create a contemplative space where the viewer can have an emotional dialogue with the images of my mother and father. Empathy is a significant element in the piece because it establishes a bond between the characters and the spectator, regardless of their individual and separate experiences. The pull of the portraits can lead to a better understanding of my parent's personal and specific situation. The spectator is more likely to care about the challenges inflicted on my parents, and as a result, begin thinking about the external, societal and cultural factors that have contributed to their struggles. 


\section{Private and Public Space}

I would like to describe the ways in which my project blurs the line between public and private space through content and form. Further, I would like to address the purpose and implications of disclosing such a personal story. Since We Last Spoke is an autobiographical project, thus the personal moves into the cultural, the private becomes the social. I am exposing fragments of my family's private life to the public. Domestic space bleeds into the public space of the gallery. According to Gaston Bachelard in The poetics of Space the home is the epitome of intimate space, understanding our experience within the space of the home enables us to comprehend the core of our being. It is a space that encapsulates our thoughts, memories and dreams. Bachelard states "Now my aim is clear: I must show that the house is one the greatest powers of integration for the thoughts, memories and dreams of mankind." ${ }^{17}$ With The Bedroom Scene, I am inviting the audience into the private space of the bedroom. Although my parents are not visually present in this scene, their bed - arguably their most intimate possession - is foregrounded in the shot. The letters in The Letter Reading are private documents that were not written with the intention of being publicly displayed. The audience isn't exposed to the content of the letters; however, they are exposed to a private moment of reflection, vulnerability and emotion induced by the documents. By revealing these intimate moments, objects and spaces in my work, I am challenging the notion of private and public. Throughout my childhood my parents have made a considerable effort to maintain our privacy. This meant that familial issues were

\footnotetext{
${ }^{17}$ Bachelard, Gaston. The Poetics of Space. Boston: Beacon Press, 1964, 6.
} 
not to be discussed with members outside our immediate family, even in moments of need. If we were to expose ourselves, our family integrity would be compromised. Our preoccupation with privacy prevented our family from engaging with outside communities, thus creating a condition of isolation and alienation. Over time we have grown out of these habits and have benefited from this shift in perspective. By confronting our secrets and establishing lines of communication with thoughtful individuals outside our immediate family, we have discovered the importance of honesty and community. In their essay Ethics and the Perception of Ethics in Autobiographical Film, John and Judith Katz express the necessity of autobiographical filmmaking, stating " in terms of the public's right to know. Private life at the end of the twentieth century is surrounded by a high degree of secrecy...We compare ourselves to myths, not reality... The value of knowing, in more realistic fashion, about other people's interior lives is unquestionable. ${ }^{\prime 18}$ By sharing a fragment of my family's personal life, I am offering the public a window into a real experience and in doing so, validating our personal history. Within public discourse, the diversity of personal and familial narratives can be scarce and this is problematic. Michelle Citron expands on this concern, stating "The honest autobiographical film or video publicly speaks about the socially hidden...This is implicit threat that autobiography poses to the status quo. As a culture, we have been little able to tolerate the truth of the variety of lived experience: that truth threatens social order. ${ }^{" 19}$ The stresses endured by immigrant families are often

\footnotetext{
${ }^{18}$ Katz, John Stuart; Katz, Judith Milstein. "Ethics and the Perception of Ethics in Autobiographical Film." In Image Ethics: The Moral Rights of Subjects in Photographs, Film, and Television, ed. Gross et al. Oxford University Press, 1991, 128.

${ }^{19}$ Citron, Michelle. "Fleeing From Documentary: Autobiographical Film/Video and the 'Ethics of Responsibility”." In Feminism and Documentary, ed. Diane Waldman and Janet Walker, Minneapolis: University of Minnesota Press, 1999, 272.
} 
overlooked and don't occupy much space in public discourse. Since We Last Spoke exposes the difficulties my family has faced due to migration and displacement. This exposure contributes to the selection of existing narratives about families and domestic life, and draws attention to the social and cultural landscape that allows for such conditions. 


\section{Chapter 3: Methodology}

My piece originated through a series of experiments. Since We Last Spoke was not a premeditated work. When I first began thinking about this project I was concerned with identity politics and my own sentiments towards the home I was raised in. My parent's relationship was not intended to be the focus of the piece. This piece was very much a process of discovery. Since I was not set on a specific form for the project, I was perpetually open to new ideas and perspectives. My process entailed of thinking of a concept, trying it out and determining if it succeeded or not. My ideas branched out from certain themes I was interested in exploring, they included: the body within spaces, cultural displacement and familial intimacy. Chronologically my process could be divided into two terms: before the letters and after the letters.

\section{Before the Letters}

Before I knew about the letters my parents wrote one another around twenty years ago, my MRP took a different shape. It was an experiment that explored bodies within the space of the home. I was interested in the idea of the home acting as a separate micro society that governed independently from the one outside its borders. My interest stemmed from questioning my personal experience in the home I was raised in. Spending some time away from home in recent years made me conscious of the tensions and misunderstandings that existed within my household. Although I value the many lessons my parents taught me and owe much of my critical perspective to their influence and 
guidance, I gradually began to understand that there was a disconnect between my principles and that of my parents. This disconnect was what I was interested in exploring. I was specifically interested in investigating this tension through a study of my body and the space of the home. I was concerned with the body because I found that the source of many of our disagreements was my body - a female body. Confining the sexual nature of my body seemed to be a priority for the whole family. Growing up, it sometimes felt as though I was being punished for having something I had no control over. I realize now, that my parent's intention was not to disempower me, but that these decisions were a symptom of the culture they knew and were a part of. Thus, through performance based video work, I would use my body as a vessel to question and dismantle these frictions. I was influenced by female video and performance artists such as Lisa Steele, Suzy Lake and Ana Mendieta. These artists, among other things, questioned the normative ways the female body was represented in western society. I wanted to experiment with the representation of my own body within the micro society of my home.

Additionally, through my interaction with domestic space, I wanted to create a mood that mirrored my general sentiment towards my home. This sentiment is contradictory, it can be described as an uneasy feeling, of longing to leave but also, of wanting to conceal myself within the safe space. I began filming videos of myself within my home in atypical configurations. (fig.1) My body represented the tension of my female identity, as well as the tension generated by two opposing cultures coexisting under one roof. Although, I was inspired by the results of these video pieces, I felt the need to investigate further and ask questions regarding how these tensions came to be. And so, I began 
conducting and recording informal conversations between me and my parents. I didn't have the intention of using the audio in my work. The conversations were research material, meant to stimulate ideas for performative works. However, many of these conversations exposed rich information regarding our family history and each of our personalities. Although we have our differences, my family has always been open and candid with one another. What I value most about my relationship with my parents, is my ability to voice my opinion comfortably, this sentiment is generally reciprocated. Our unreserved dynamic has made for some very interesting conversations. Thus, I thought it would be an easy process to capture these discussions. This was not the case. Often times, as soon as I began recording, the tone of the room would change. It wasn't that they were more reserved, in fact it was the opposite. My parents took this opportunity to state their side of the story, often exaggerating past events and manipulating facts to align with their point of view. Frustrating as it was, it was interesting to witness their eagerness to express themselves. Fortunately, over time, my parents' awareness of the recorder dissipated, this resulted in more honest and meaningful conversations. For the first time ever I was beginning to understand my parents as individuals not just as my guardians. Speaking with them now, it seems as though we all benefited in some way from these conversations. The timing of these discussions could not have been more crucial. Each of us - my mother, father and myself - were going through a transformative and defining period in our lives. If I were to document our conversations in the present time, I don't think the outcome would be as illuminating. These conversations allowed us to step out of the realm of the everyday, to pause, reflect and reevaluate. Perhaps, these moments of 
deep reflection influenced and benefitted our resolutions for the future. In in the end, I decided to include bites of the recorded audio in the work.

The visuals of these video works evolved throughout the months. They were informed by the conversations with my parents and their ideas regarding the concept of home and family. I began experimenting with objects belonging to Iranian culture around our family home. I decided to work with objects because they possess a history of their own. These cultural objects are associated with a culture and history that transcends the one in the home they reside in. I am familiar with their superficial qualities - since I grew up among them - but my understanding of them does not surpass this basic comprehension. For my parents, they have a different meaning. They have a relationship with these objects outside our family home. My mother and father curated their collection of pieces and brought them to Canada from their homeland. When they are amongst these objects they may be transported back to a different time and place in their lives. These objects are nostalgic items. Further, they have a better understanding of their usage, function and antiquity. Thus, these objects were the perfect symbol of the cultural gap between my parents and I. I was eager to demonstrate my unfamiliarity with my homeland through these objects and performance. I began thinking about and researching Freud's idea of the uncanny or the unheimlich, which refers to the strangely familiar. Freud states, "the 'uncanny' is that class of terrifying which leads back to something long known to us, once very familiar" ${ }^{20}$ I recognize the objects as having having a place in my domestic life - familiarity - but at the same time, the full cultural context that gives them meaning

\footnotetext{
${ }^{20}$ Freud, Sigmund. "The 'Uncanny'." In The Standard Edition of the Complete Psychological Works of Sigmund Freud, Volume XVII (1917-1919): An Infantile Neurosis and Other Works, Vintage; New Ed edition, 2001, 219.
} 
is not accessible - thus making them "strange" - there is a definite and uncomfortable emotional tension implied. This feeling of anxiety surrounding the familiar or home was what I was attempting to translate in my video works. For instance, one of the video works I created involved me pouring tea into a traditional Iranian tea glass called an Estekan (fig.2). Tea has a very rich history in Iran and a ubiquitous presence in Iranian homes. Drinking tea is a common and communal ritual that fosters warmth and affinity between individuals in Iranian culture. However, in my particular piece the glass or Estekan was meant to break and shatter to pieces while I poured the tea. The familiar and comforting scene would be ruptured, creating an "uncanny" mood. The way I attempted to break the glass was by freezing the glass then pouring boiling hot tea into it. This condition causes the glass to break. However, in this particular case, I could not get the glass to crack. After several attempts, I finally gave up on this idea. Although this specific experiment did not pan out, I wanted to continue working with symbolic objects and performance.

Another video work I created was a durational piece that involved me rolling and unrolling a Persian rug continuously, until I reached a point of exhaustion (fig.3). This work was meant to represent the mental frustration caused by immigration and acculturation. A conversation with my father prompted this idea. In our discussion my father was telling me about his immigration experience and the difficulties he has had sharing his native culture in a new environment. The piece was set in a North American home, the presence of my body and the ornamented rug came in stark contrast with the clean suburban backdrop. The act of unrolling and rolling the rug related to how much or 
how little foreign citizens reveal their native culture in the host country and how emotionally draining these decisions can be. The video work was a good start but I felt it needed to be fleshed out more. I wanted to include the audio recording of the conversation I had with my dad that inspired the piece. I tried matching the audio of my father discussing his immigration experience with the visuals of the rug piece, but when compiled, the piece fell flat. Therefore, I continued my explorations.

Intimacy between family members was another concept I was interested in exploring. To do so, I tried to think of moments of intimacy I shared with either of my parents throughout my childhood. I had the intention of recreating and filming these moments and examining the outcome. A memory that came to mind, was the daily routine of my mother fixing my hair in the morning before I went to school. Although this activity seems common and mundane, it allowed for an intimate exchange between mother and daughter. In addition, this act demonstrated the authority my mother had over me. I was not allowed to look any other way than the way my mother thought I should look. I had to appear and behave appropriately, especially in public spaces. I did not have agency over my appearance. This mixture of affection and domination is what interested me. I recreated this scene with the help of my mother. I set up a tripod and asked her to brush and fix my hair like the way she did when I was young (fig.4). Although the camera caught glimpses of genuine intimacy between us, the overall results felt contrived and artificial. And so, I had to move on. 
I created a similar and more successful piece with my father. The piece was initiated by yet another conversation I had with him. This particular conversation turned into an argument - something I did not plan. During this session I asked my father about my childhood and his experience fathering me throughout the years. Unanticipatedly, he began performing. I felt as though his answers were dishonest and misleading. This was not the kind of discussion I was hoping for, and so, I shut down. Leaving the recorder on, I did not say a word, I was frustrated and began doubting the whole project. Soon the conversation took a turn. My father distracted by my hostility, forgot about the recorder and shifted his behaviour, he was now the comforting and fatherly character. Throughout the rest of the recorded conversation my father earnestly attempted to get me to speak and voice my emotions. While editing, I selected and sequenced parts of the recorded audio where my father tried to get to me to communicate. For the visual component, I asked my father to join me as I revisited a trail we frequented when I was younger. The location holds many memories between my father and I. Thus, it seemed liked an appropriate place to return to. I set up the tripod, and asked him to wander around the forest with me while the camera filmed us. I compiled the edited audio with the visual of me and father roaming around the desolate forest trail. The final piece ended up being a gentle meditation on our relationship and his role as my father (fig.5). This piece was successful but completely ephemeral and unplanned. I realized that I wasn't necessarily interested in recreating already lived moments with my parents. I was more so interested in setting up a situation where new and genuine exchanges can take place. 
When I would run out of ideas, I would always return to the conversations. They were the foundation of all my pieces. In these conversations we discussed everything from our relationship, to their childhoods to my childhood. One of the main conversation topics was the state of my parents' marriage. Throughout this time my parents were in the midst

of considering a divorce. As mentioned, my mother and father had diverging expectations for their future together. My father's reluctance to let go of his life in Iran conflicted with my mother's wish to fully establish a life in Canada. After years of treading around this conflict of interest, a decision had to be made. I would have discussions with both of them individually about their turbulent relationship. Growing up, this was often my role a mediator. In many ways, Since We Last Spoke is a reflection of my role as peacekeeper and negotiator within the family dynamic. These conversations were revealing and difficult but I was accustomed this type of disclosure by my parents. In one of these conversations by mother mentioned letters her and my father had written one another during the time they were moving to Canada (fig.6). I knew immediately that I wanted access to those documents. I wasn't sure how I was going to use them, and so I held on to them for a few weeks, contemplating different ways I could incorporate them in my work.

\section{After the letters}

During the period in which I found out about the letters, my father had just returned from one of his trips to Iran and was residing in a separate place from my mother. Throughout his visit, my mother and father would get together during the days and discuss their plans 
for the future. On one of these occasions I decided to tag along and bring the letters, a camera and tripod with me. I had the idea of asking them to choose a letter out of the pile and read it aloud to the other person while I filmed their reactions (fig, 7). The letters are documents that represent past dialogues between my parents. They point to a specific time in their lives, the beginning of their marriage. In them, they wrote about what they hoped for their future and plans on how to realize their wishes. Unfortunately, many of the aspirations stated in the letters are still unachieved. These documents are emotionally charged and as soon as one of them began reading, the other replied with their expression. Their reactions were instant, profound and emotional. Further, the letter reading provoked an intense conversation between the two of them that I was able to record. Once again, I managed to set up a situation that initiated a new, genuine and ephemeral exchange between my parents and me. In this work, I used old memories between the two of them to create a new memory between the three of us. This situation could not be recreated, the timing and mood was essential and fleeting. After this event, I felt confident that I had the footage I needed to complete my project. The remainder of the work would be done in postproduction.

At this point, I had put aside my original intention of creating a performance-based work. I realized that it wasn't the right medium to express such an intimate and urgent project, at least not at this time. I recognized that this piece wasn't about me anymore; it was about my parents. It did not seem appropriate to incorporate my body in the work. However, even though I am not physically portrayed in the piece, I do have a presence. If it weren't for my instruction, this exchange would not have taken place. The moment I captured was not completely spontaneous, as if I was a fly on the wall. I played a key role 
in creating this scene. Thus, I do believe there is a performative and directional element in the piece. Their compliance to go ahead with what I have asked them also says something about our relationship. Perhaps they compromised their own comfort because of my role as their daughter and they felt obligated to support my creative endeavors. Or rather, they may have seen value in this experiment for their own relationship. Regardless of their motives, I think we were all surprised by the outcome.

Once I acquired the footage, I had to figure out the form and how I was going to effectively interpret what I had captured. After replaying the shots of my parents' reaction in the editing room, I realized I did not want to include the audio in these moving portraits. Part of this decision is enforced by my inability to read or write in Farsi. I was never able to read the content of the letters on my own. Even when I had the letters translated to English, much of the meaning and essence of my parent's words are lost in the translation. Farsi is known to be a language that frequently employs metaphors. Most of these metaphors loose their meaning when they're translated to English. In the past, my father has mentioned his frustration concerning his attempts to translate certain Iranian poems and expressions to me. He states that I must have a deep understanding of Iranian culture and even to have had spent some time in Iran to truly understand the meaning of certain expressions and metaphors. I believe that my distance from the language encouraged me to focus on other elements in the footage. As a result, I was fixated on their facial responses. Further, the exclusion of audio was a conceptual decision. The silence would act as a metaphor, replicating the silence that enveloped my childhood home. 
Although I found the portraits to be compelling on their own, I felt the need to give the audience some context, especially because of the absence of the accompanying audio. I wanted to point to the broader external factors that have contributed to their predicament. I found that the recorded audio of the subsequent conversation between my parents offered valuable information about a married couple navigating their lives between two worlds. Their tone and poignant statements revealed a desperate longing to come up with a solution, to finally choose what life they want to lead. I made the decision that excerpts of this conversation would be the other feature in the work. I wanted the audio to be accompanied by a visual component. After some deliberation as to what the visuals would be, I returned to the idea of the home, the space that witnesses and holds these discussions. Their bedroom seemed to be an appropriate location. The bedroom is a spatial embodiment of my parents' relationship. It is in their bedroom that they share their most intimate and private conversations. It only seemed appropriate for me to match the footage of their bedroom with the audio. However, I was faced with an obstacle. My parents didn't live in their old home anymore. There was no family home. My mother is living by herself in a temporary rented space. Fortunately, I had filmed some footage of their old bedroom before they sold our house. This footage was from when I was experimenting with performance and domestic space. I wasn't interested in using a static image of the room. I wanted movement in the image. Ideally, I wanted to somehow demonstrate the passing of time; a time lapse shot of the room going from day to night. However, my shots of the space only lasted a few minutes rather than 24 hours and I no longer had access to that room. I did have a few minutes of the room shot with an open 
aperture and a few minutes of the room shot with a smaller aperture. I blended these two shots in after effects and created a scene that portrayed a room subtly changing from light to dark (fig. 8,9) The transition from light to dark can be read as a both a metaphor for the progression of time, as well as, the paradox of dark and luminous moments in a relationship. The marital bed portrayed in this image also acts as a metaphor. Their disheveled bed, with only one pillow resting on top represents the tumultuous state of their relationship.

Together, the silent portraits and bedroom scene make up the installation. The piece is a three-channel installation. Upon entry the viewer is confronted with two separate and silent moving portraits that are projected on opposing walls and a still image of my parent's bedroom on the wall opposite of the entrance. Once the moving portraits come to an end, the projections fade to black and the bedroom scene commences. These two components will be continuously playing on an uninterrupted loop. The letters they read will be visible in a glass vitrine in . I have included the letters as evidence, but preserved their privacy by placing them behind glass. Viewers can interact with the physical embodiment of time illustrated by the disintegrated paper. Spectators who speak Farsi and are familiar with the language have the advantage of reading some of the content of the letters. However, their arrangement within the vitrine will not make them very accessible. This is done purposefully, the content of the letters are not meant to be an essential element, the emotional impact they induce is the focus of the installation.

I would now like to discuss why I chose to interpret this piece through multi-screen video 
projection. I decided on an installation rather than a one-channel film because of my preoccupation with space. I wanted to loosely replicate the intimate space of the home. The use of more than one wall has the capacity to envelope the spectator. In The place of artists cinema Maeve Connolly states "It is not unusual for multi-screen video installations to refer directly to a specific place that exists, or once existed, elsewhere.,"21 I believe the architecture of the gallery space fortifies the sense of a specific place - my family home. Furthermore, looping the scenes allows me to play with the temporality of the piece. There is no marked start or finish. The spectator can walk in while the bedroom scene is playing or when the portraits are playing. Their experience of the piece as a whole can alter, depending on which scene they encounter first. I believe this makes for a more interesting viewing experience. In addition, I wanted the spectator to be an active participant in the work. By projecting my parents' portraits simultaneously on opposing walls, I am placing the viewer in the cross fire of their silent dialogue. I'm asking the spectator to make an active choice - whom do they want to pay attention to? This positioning of the spectator is a comment on my own position within the family.

The concept of home is woven into every breath of Since We Last Spoke. Our family home in Canada is the space where my family and I developed our relationships and where are memories were created, both good and bad. However, home is more than just the space we physically occupy. Symbolically, home is a space where we feel most at peace, somewhere we can trust, somewhere we belong. In this regard, I believe my mother and father have conflicting ideas on what home constitutes. From what I have

${ }^{21}$ Connolly, Maeve. The Place of Artists' Cinema: Space, Site and Screen. Intellect Books, $2009,64$. 
gathered, I don't believe our physical house in Canada will ever be home for my father. He has an undeniable attachment to his life in Iran. It is in Iran where my father feels most comfortable and supported. Speaking with my mother throughout the last few months it has become clear that she considers home to be her family, location is not necessarily relevant. For my mother, the security of home depends on the bonds between family members, nurturing our relationships is the underlying necessity of her concept of home. In Since We Last Spoke I've attempted to demonstrate the symbolic notion of home by portraying our physical home in the installation and by using an actual space to create an immersive sensation of an intimate space. 


\section{Chapter 4: Relevance}

My installation is connected to the realm of autobiographical documentaries. However, the form in which I have chosen to execute this project challenges traditional documentary forms. Although the work is rooted in reality and evidence, it's execution plays with performance and manipulation of sound and image. Artists that have influenced my work include: Sophie Calle and Mona Hatoum. This section of my thesis paper will discuss the works of these artists that have inspired my form and play with content. Sophie Calle's artistic practice is known for it's autobiographical content and performative execution. In her piece Prenez soin de vous Calle has asked 107 different women to analyze respond to a breakup letter Calle had received from a former lover. This piece stemmed from Calle's inability to process this heartbreaking information on her own. Calle reached out to other women for support and as a result created a piece that blurs the boundaries between private and public. In addition, Calle is playing with the letter as an archival document. In Performance in Sophie Calle's Prenez soin de vous, Shirley Jordan discusses' this merging between public and private in Calle's piece stating "Calle arranges multiple reenactments of the moment of reading, wrenching it from the intimate space/time of private reception, exhibiting it and opening it to public scrutiny, representation and performance."22 Further, Jordan explains the importance of community within Calle's work, "If the satisfaction of the romance script is not available in Calle's piece, there is nevertheless a different script which supplants it: that concerning

22 Jordan, Shirley. "Performance in Sophie Calle's Prenez soin de vous” In French Cultural Studies, 2013, 251. 
the pleasures of a larger community of women and the vigorously therapeutic power of women's conversation and narrative. Calle's reception of the message is repeatedly replayed, discussed and reconfigured. ${ }^{, 23}$ Like Calle's piece I have created a score in The Letter Reading. While Calle has asked members of an outside community to read, analyze and respond to an intimate letter of hers, I have asked my parents to reread intimate letters they have written one another as a young couple.

The work of artist Mona Hatoum has also influenced my work, in particular her piece Measures of Distance. Mona Hatoum is a Palestinian artist who was born in Lebanon and currently works in Britain. Thus, she too understands the struggles of displacement. Hatoum works in performance and video but also creates large-scale installations and sculptures. Her video work is concerned with the division between the west and east. Her work often speaks of exile, displacement and loss. Measures of Distance is a video work that comprises of images of Hatoum's mother in the shower. Layered on top are letters written by Hatoum's mothers who resides in Beirut to her daughter in London. The letters scroll down the screen in Arabic while Hatoum reads them aloud in English. The work also consists of taped conversations in Arabic between mother and daughter, in which her mother speaks openly about her feelings, her husband and her sexuality. Like my piece, Hatoum's work is intimate and autobiographical. Further, Hatoum has manipulated video and sound but layering recorded conversations on top of disjointed visuals. In Shaking up' vision: the video diary as personal and pedagogical intervention in Mona Hatoum 's Measures of distance Mehre Y. Khan discusses the motives and implication of Hatoum's 
form stating "Hatoum combines modernist art practices (that is, collage) with postmodern theoretical concepts (such as, the fragmentation of meta-narratives) in order to critique the racist, sexist, and colonialist underpinnings of both. Moreover, her reenactment of the routines of cultural displacement in the video not only occurs during the process of copying, transferring, and transforming photography and audiotape to videotape, but in her method of visually decoding the spoken tongue of her mother into English and then relocating these 'speech acts' (Butler, 1997) back onto a body 'unrelated to Western capitalist emotional, moral and social references' (Bannerji, 1995, p. 166). ${ }^{.24}$ Both these artists exhibit autobiographical work. The aforementioned pieces depend on archival documents and experiences grounded in reality. However, they both play with these materials in innovative ways, such as the use of a score and video and audio manipulation. In my installation I approach my content in a similar fashion. I believe that by interpreting my family's story through new forms of documentary I am able to shed light on the challenges we have faced while also bringing forth integral concepts imbedded in our biography.

\footnotetext{
${ }^{24}$ Khan, Y. Mehre. “' 'Shaking up' vision: the video diary as personal and pedagogical intervention in Mona Hatoum’s Measures of distance” In Intercultural Education, 2007, 324.
} 


\section{Conclusion}

Preceding the making of Since We Last Spoke, my parents and I have had extensive conversations about the work. My main concern is how they feel about the final piece and if they are comfortable with the outcome. In their response they tell me that I have caught them in a very particular time in their lives. That what I have captured in Since We Last Spoke is just a fraction of a much larger and fluctuant life. I believe this to be true. The public will never know or understand my family's personal history in it's entirety. That was never the objective. I have offered the public a limited window into our lives to point to broader social and cultural circumstances that create strenuous environments for migrant families. Since We Last Spoke is an intimate installation that provokes questions concerning the impact of migration on familial life through a meditation of my parents relationship.

This project began as an interrogation of my own position within my family. However, through the process of creating my piece I came to realize that in order to understand and locate my place I had to first examine the foundation of our household. It is through this examination that I was able to create an alternate space for my family and me to communicate and begin to understand our differences. This project gave my family an excuse to take a pause and communicate in an unfamiliar mode. The objective of our conversations was no longer to prove our point, to conquer or dominate. We spoke to understand, forgive and to negotiate our differences with generosity. 
In our current era, migration is a constant, steady effect of the modern mode of life. This reality means that more and more families are endowed with the burden of managing multiple, diverging expectations and ways of being. Seldom having support from external communities this burden can take its toll and eventually disintegrate the family unit. What I hoped to have achieved with Since We Last Spoke is to demonstrate the importance of communication both within the family and between home and society. 


\section{Image List}



(Fig. 1) Still from body and domestic space video performance, 2015

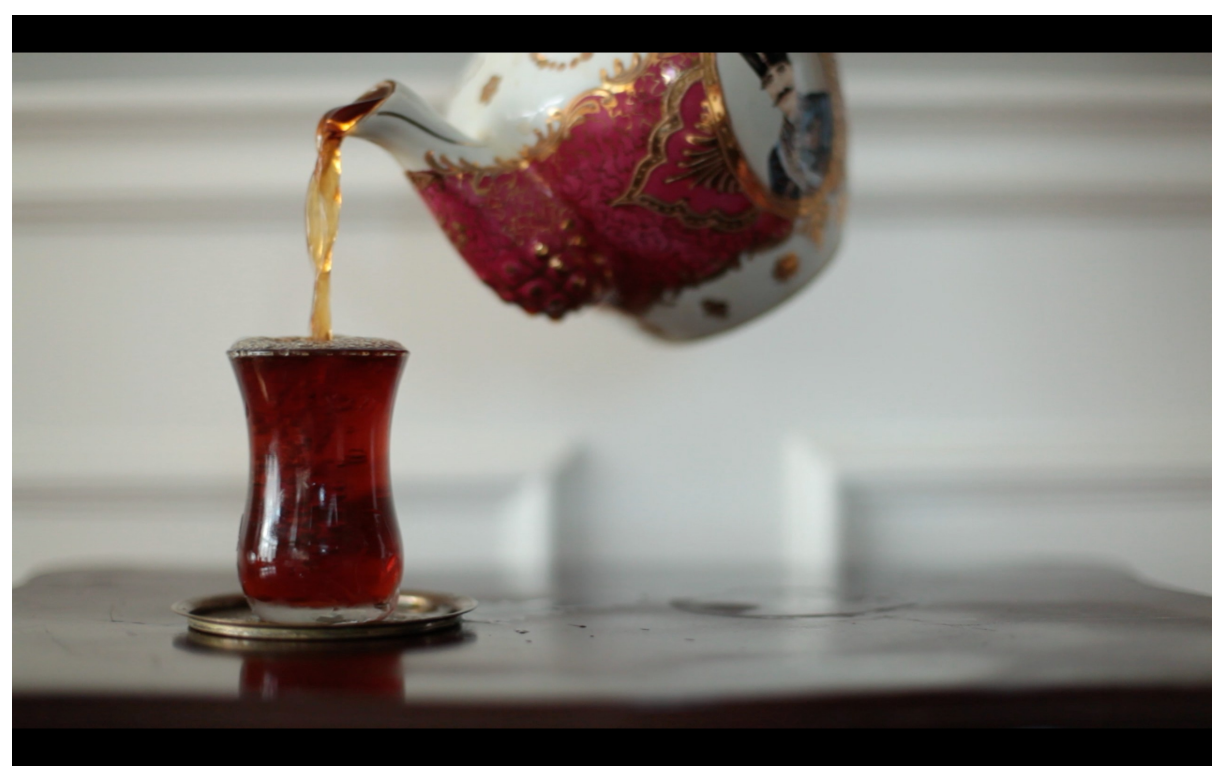

(Fig.2) Still from Estekan Video, 2015 


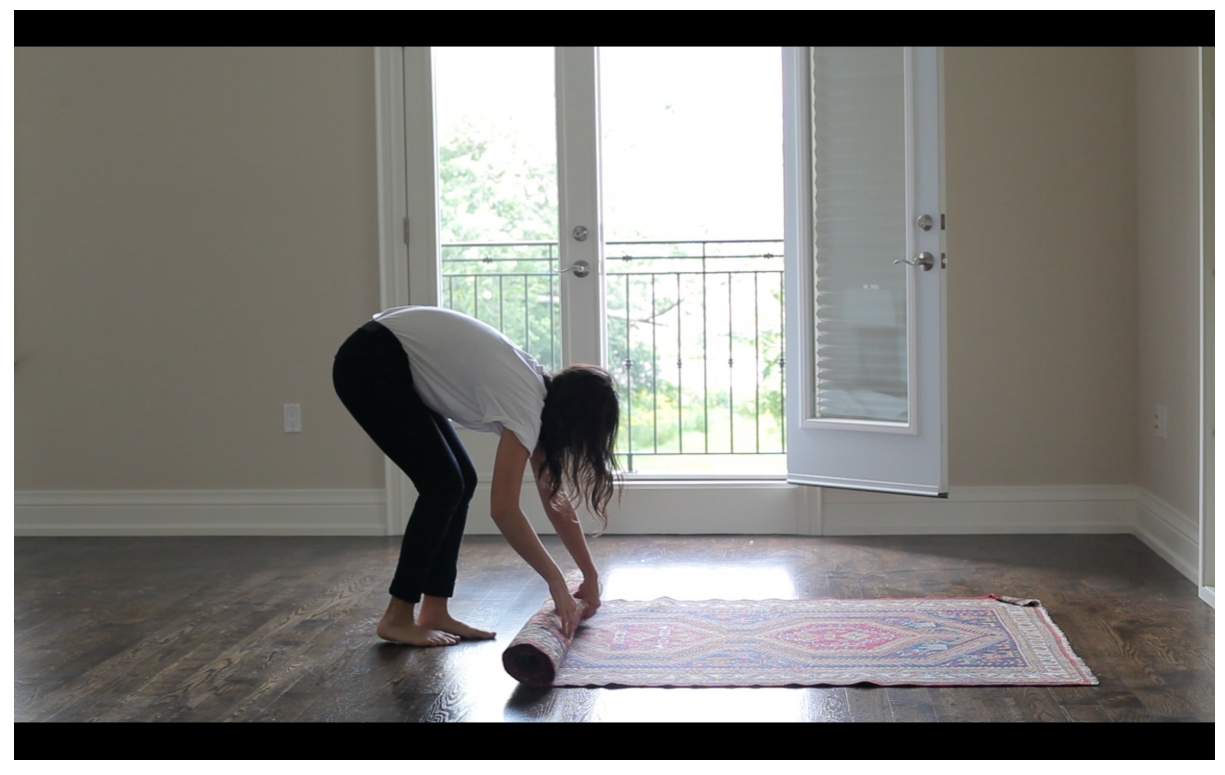

(Fig.3) Still from rug video, 2015

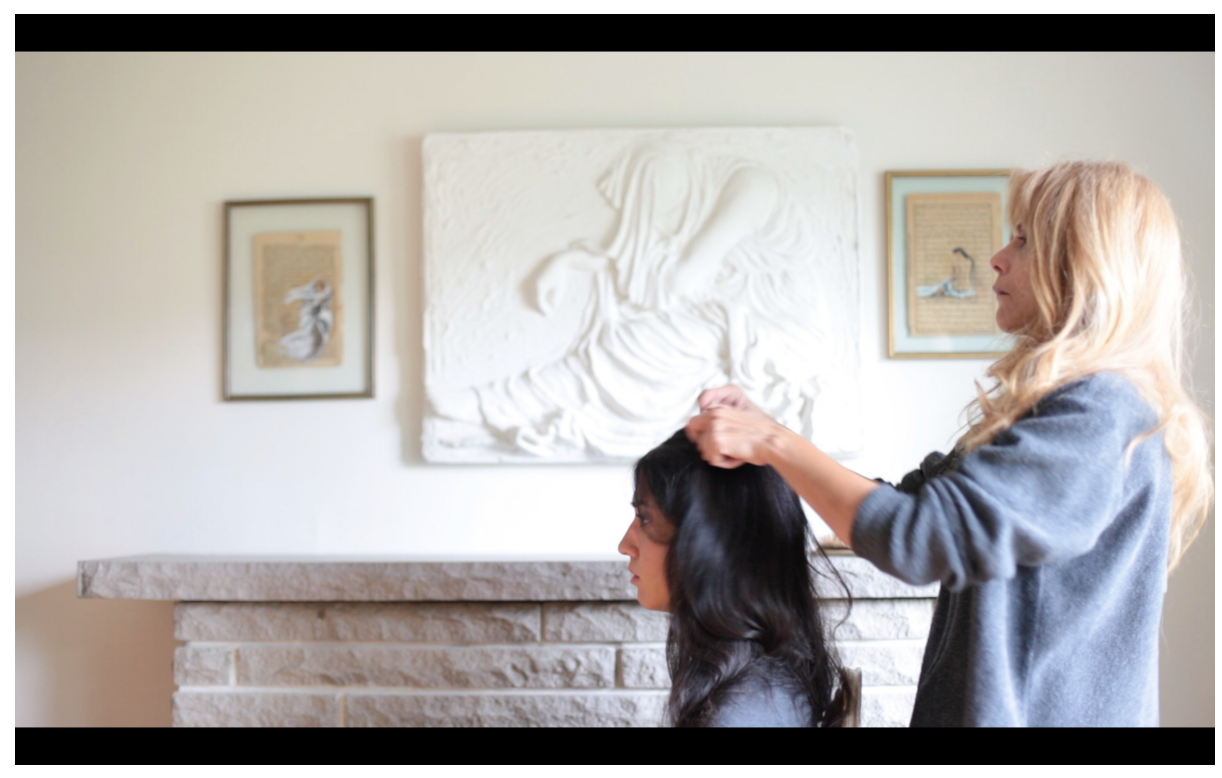

(Fig.4) Still from hair video, 2015 


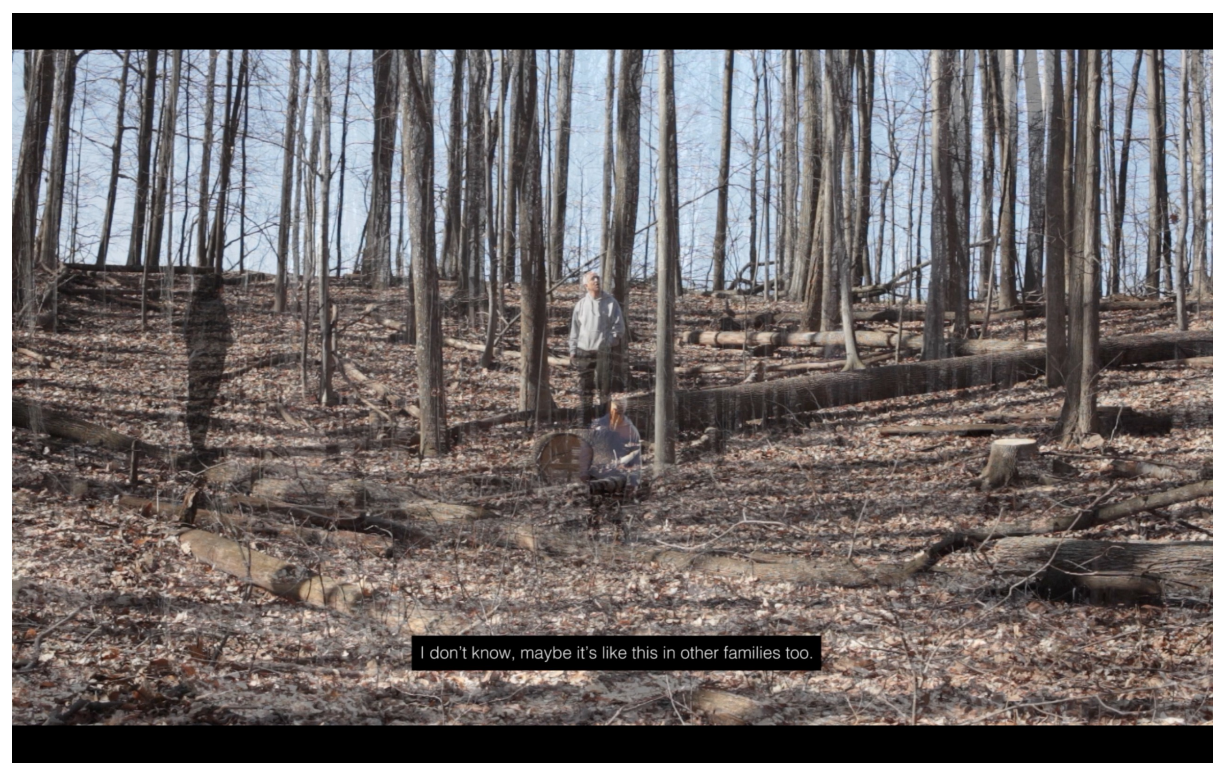

(Fig.5) Still from walk with father, 2015

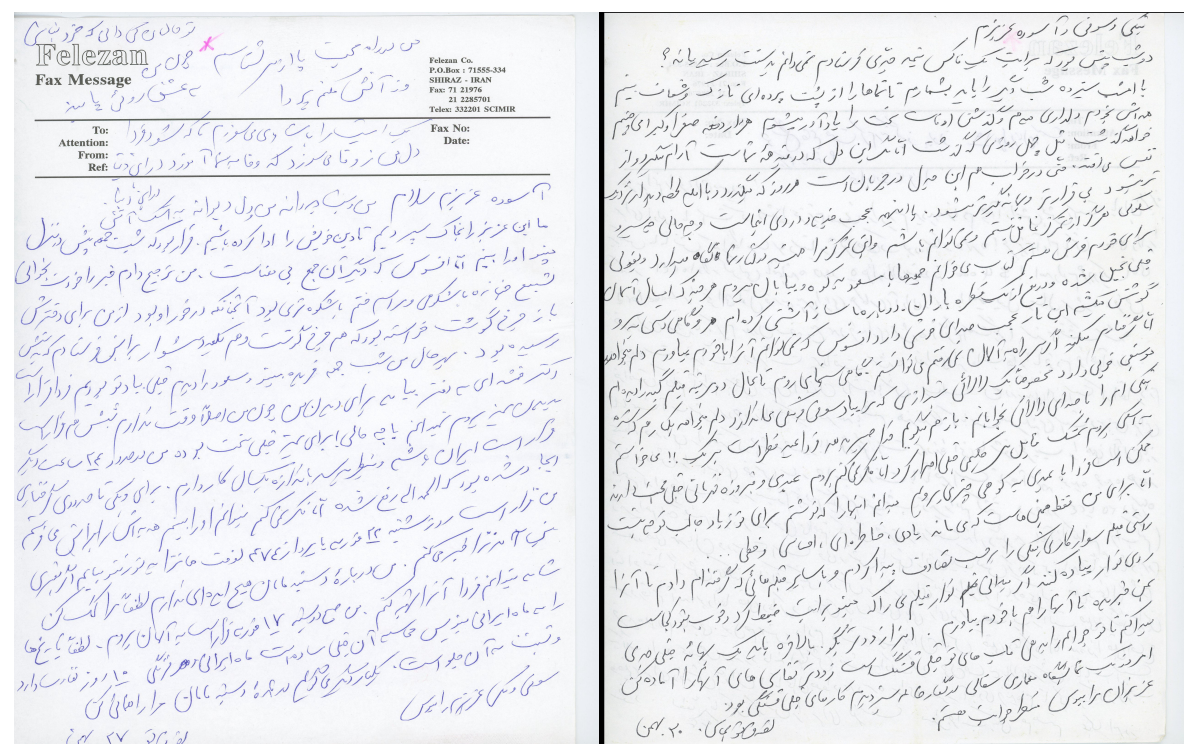

(Fig. 6) Letters written between my mother and father, 1996-2004 


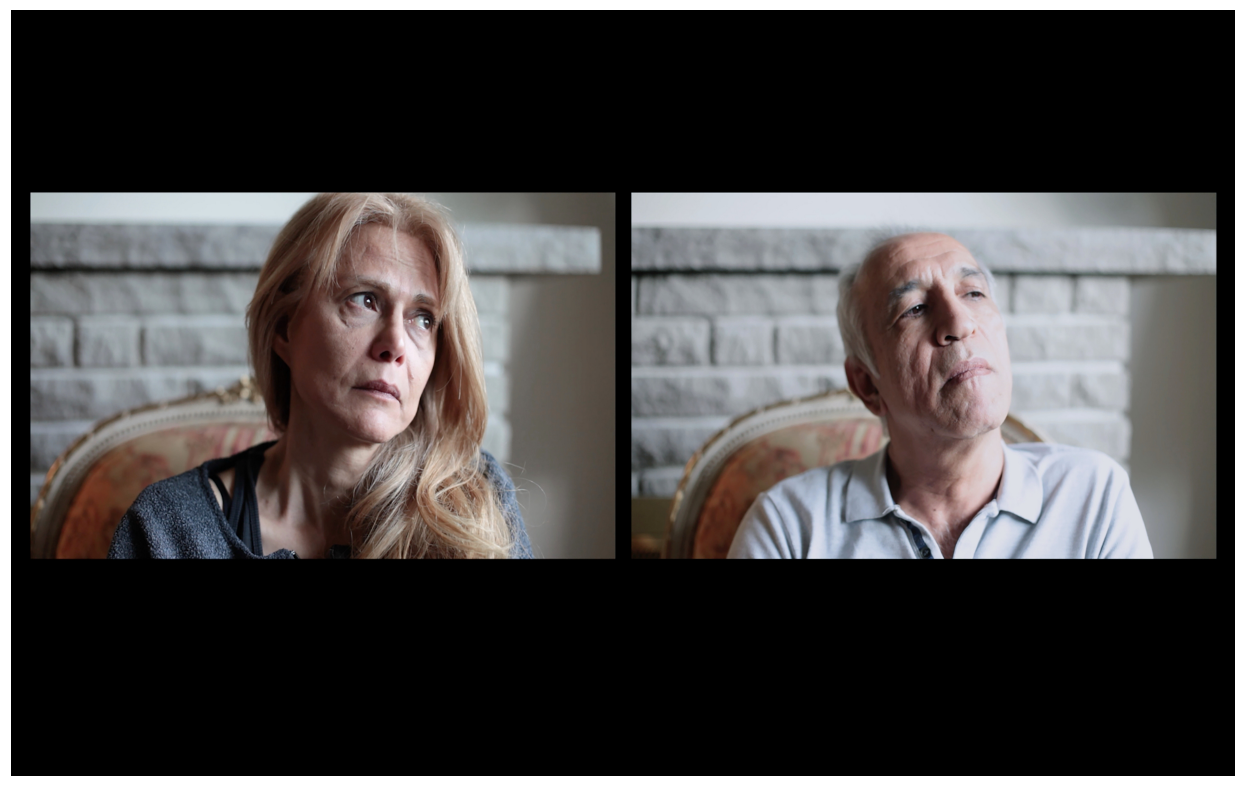

(Fig. 7) Still of my mother's and father's face during The Letter Reading, 2015

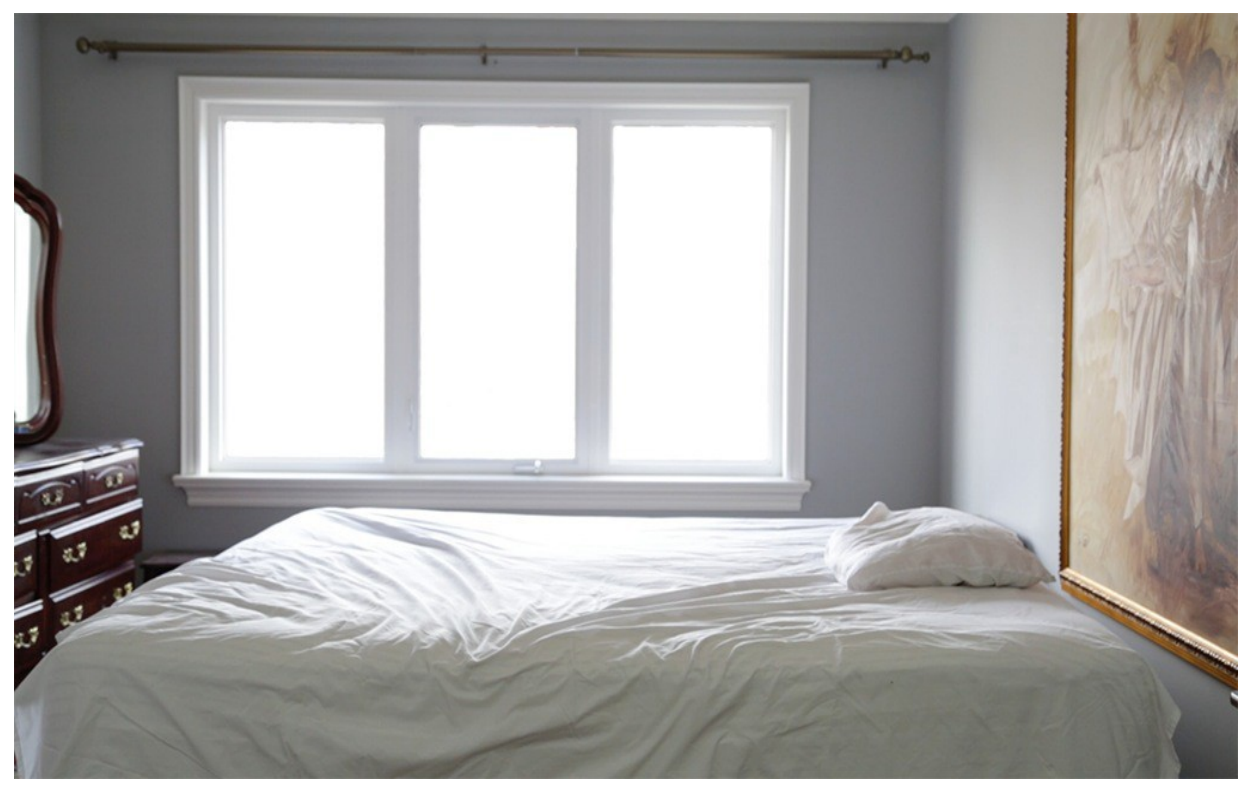

(Fig.8) Still from The Bedroom Scene (light), 2015 


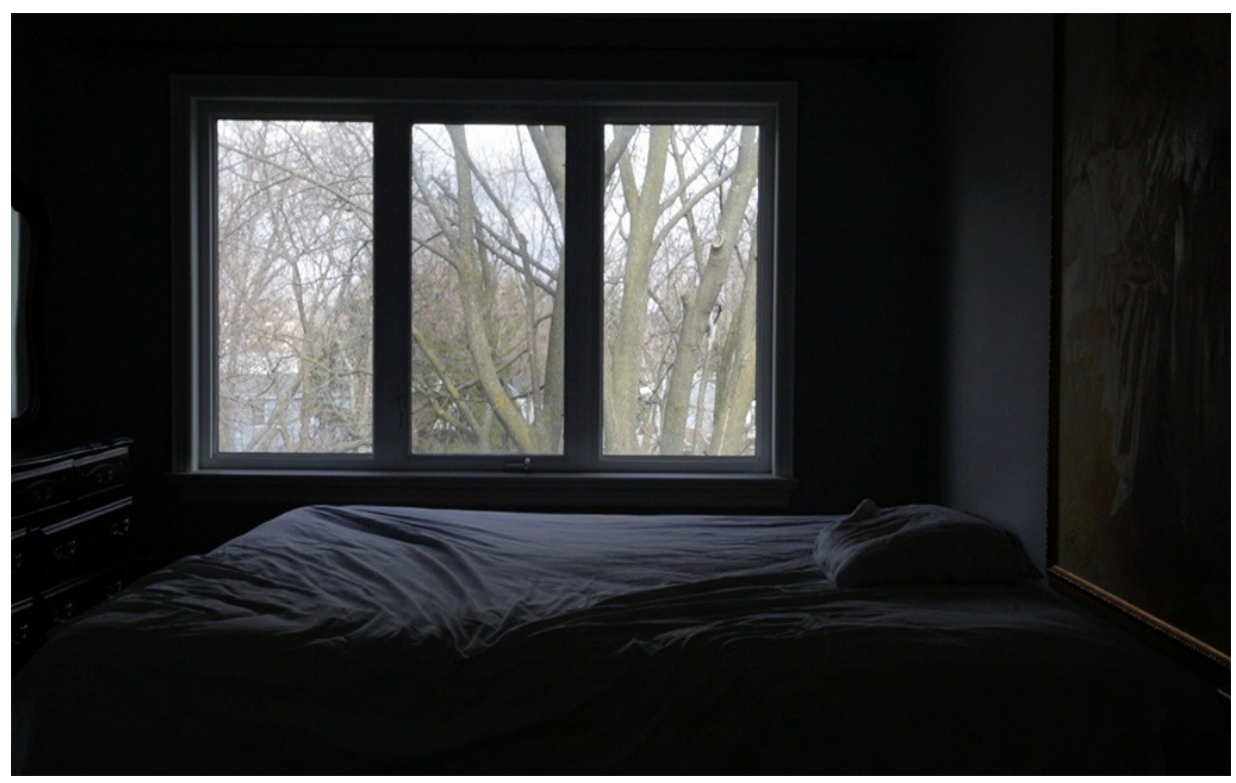

(Fig.9) Still from The Bedroom Scene (dark), 2015 


\section{Bibliography}

Bachelard, Gaston. The Poetics of Space. Boston: Beacon Press, 1964.

Citron, Michelle. "Fleeing From Documentary: Autobiographical Film/Video and the 'Ethics of Responsibility'.' In Feminism and Documentary, ed. Diane Waldman and Janet Walker, Minneapolis: University of Minnesota Press, 1999, 271-286.

Connolly, Maeve. The Place of Artists' Cinema: Space, Site and Screen. Intellect Books, 2009.

Freud, Sigmund. "Mourning and Melancholia." In The standard Edition of the Complete Psychological Works of Sigmund Freud, Volume XIV (1914-1916): On the History of the Psycho-Analytic Movement, Papers on Metapsychology and Other Works, 237-258.

- "The 'Uncanny'." In The Standard Edition of the Complete Psychological Works of Sigmund Freud, Volume XVII (1917-1919): An Infantile Neurosis and Other Works, 2001, 217-256.

Ghaffarian, Shirin. "The acculturation of Iranian immigrants in the United States and the implications for mental health." In The Journal of Social Psychology, 138(5), 1998, 645654.

Hojat, Mohammadreza, et al. "Gender Differences in Traditional Attitudes Toward Marriage and the Family : An Empirical Study of Iranian Immigrants in the United States." In Journal of Family Issues, 21(4), 2000, 419-434.

Hooks, Bell. Outlaw Culture: Resisting Representation, Routledge Press, 1994.

Jalali, Behnaz. "Iranian Families.” In Ethnicity and family therapy, edited by M. McGolderick, J. K. Pearce, \& J. Giordano, New York: The Guildford Press, 2005, 451486.

Janan, Tina. "The Difficulties of Traditional Iranian Parents Have Raising Their First Generation Daughter in the United States.” The Chicago School of Professional Psychology, 2013.

Jordan, Shirley. "Performance in Sophie Calle's Prenez soin de vous" In French Cultural Studies, 2013.

Katz, John Stuart; Katz, Judith Milstein. "Ethics and the Perception of Ethics in Autobiographical Film." In Image Ethics: The Moral Rights of Subjects in Photographs, Film, and Television, ed. Gross et al. Oxford University Press, 1991, 119-134.

Khan, Y. Mehre. “' 'Shaking up' vision: the video diary as personal and pedagogical intervention in Mona Hatoum's Measures of distance" In Intercultural Education, 2007. 
Laird, Joan. "Theorizing Culture: Narrative Ideas and Practice Principles." In Journal of Feminist Therapy, The Haworth Press, 2000, 99-114.

Nassehi-Behnam, Vida. "Change in the Iranian Family." In Current Anthropology, 26(5), The University of Chicago Press, 1985, 557- 562.

Pawliuk, Nicole, et al. "Acculturation style and psychological functioning in children of immigrants.” In American Journal of Orthopsychiatry, 66(1), 1996, 111-21.

Plantinga, Carl; Smith, Greg M. Passionate Views: Film Cognition, and Emotion. The Johns Hopkins University Press, 1999, 119-134.

Sherif, Carolyn W, et al. Attitude and attitude change: The social judgement-involvement approach. Greenwood Press, 1965.

Sturken, Marita; Cartwright, Lisa. Practices of Looking: An Introduction to Visual Culture. Oxford University Press, 2001. 